Connotas. ReVISTA DE CRÍTICA Y TEORía LITERARIAS/Núm. 14-15/2014-2015

\title{
Proyectos de restitución mitológica: la antología Paisajes del limbo y la colección Singulares
}

\author{
JAVIER HERnÁNDEZ QuezAdA ${ }^{*}$
}

Resumen:

En el caso de la expresión literaria, las respuestas heterodoxas obedecen a una situación de agobio y desinterés, por lo que siempre, o casi siempre- proponen lo que se niega, lo que se excluye, en el afán de contravenir los principios establecidos por la institución. Hablando en términos específicos, esto se matiza en dos proyectos impulsados por el escritor Mario González Suárez, desde hace algunos años: nos referimos a la antología Paisajes del limbo (2001), publicada bajo el sello de Tusquets Editores, y a la colección Singulares, auspiciada por la Dirección General de Publicaciones del Consejo Nacional para la Cultura y las Artes.

Palabras clave:

Canon, antología, colección, literatura mexicana, mitología.

En las notas que a continuación expongo abordaré el tema del canon: tema central, sabemos -definitivo-, en la noción dominante de una expresividad que, entre varias cosas, determina los basamentos de su pasado y las consecuencias, medibles, de su futuro (Rabossi $73,77) . Y$ es que, ciertamente, considero (como muchos lectores) que este punto es central para comprender la imagen que tenemos

\footnotetext{
* Universidad Autónoma de Baja California.
} 
de la literatura mexicana, toda vez que legitima las aportaciones de quienes se convierten en autoridades culturales por factores diversos como la originalidad que plantean en sus obras o el influjo que ejercen no solo en otros artistas, sino también en las instituciones y los medios de comunicación por los que desfilan y hacen las veces de, según Roger Bartra,

una verdadera corte de los milagros compuesta por escapados de la academia, periodistas con ínfulas, prófugos de la literatura, ideólogos desahuciados, tecnócratas desempleados, políticos insensatos, burócratas exquisitos, y muchos otros especímenes que son vistos con alarma por una clase media timorata frente a los retos de la democracia y con desprecio por las nuevas élites políticas de derecha (18).

El planteamiento de Bartra es válido si aceptamos el papel que el creador-intelectual juega en la actualidad: un papel supeditado a diferentes instancias de poder, las cuales contribuyen -como en el caso de los medios de comunicación, repito- al fortalecimiento de un prestigio que a muchos les agradaría obtener: me refiero al del autor canónico, al del autor que se asume como alguien importante gracias al tipo de relaciones sociales que establece y a la relevancia que su obra adquiere, vista a los ojos de los demás. ${ }^{1}$ De ahí que,

\footnotetext{
${ }^{1}$ En el caso de los medios de comunicación es frecuente toparse con semejante legitimación, consistente en el aplauso y la adulación desmedida de la celebridad cultural, sobre todo si ha conquistado un lugar destacado en la esfera del arte y sus obras circulan - sin mayor problema- por las rutas comerciales del mundo global. Pero, igualmente, es necesario recordar que si alguien cae de la gracia de esta industria, trátese de quien se trate (políticos influyentes, empresarios poderosos, deportistas destacados, etcétera), las cosas cambian con facilidad, y es cuando en los medios se pasa del embeleco servil al linchamiento público, dando pauta a una "publicidad mediata" que difunde, al decir de John B. Thompson, "acontecimientos que se desarrollan, al menos parcialmente, gracias a las formas de la comunicación mediata y que de este modo adquieren una notoriedad pública que es independiente de su capacidad para ser visto u oídos de forma directa por una pluralidad de terceras personas copresentes. En virtud de esta publicidad
} 
consciente de las implicaciones de semejante determinismo, entienda que las autoridades siempre han estado ahí, en la palestra de los elegidos tanto por la facción hegemónica en turno, que reconoce públicamente-institucionalmente la importancia de un escritor, como por la subalternidad progresista que le precede, quien, ávida de contraponer sus figuras, ensalza a aquellos representantes de lo antagónicoque se adaptan al modelo consignado por Harold Bloom y que se expresa en sus posibilidades de comunicar "la extrañeza, una forma de originalidad que o bien puede ser asimilada o bien nos asimila de tal modo que dejamos de verla como extraña" (El canon 13); en sus posibilidades de influir, a la par, en los "talentos más débiles" y "transformar a sus antecesores en seres compuestos y, por tanto, parcialmente imaginarios" (El canon 21); insiste Bloom:

Los más grandes autores asumen el papel de "lugares" en el teatro de la memoria del canon, y sus obras maestras ocupan la posición que corresponde a las “imágenes" en el arte de la memoria. Shakespeare y Hamlet, un autor capital y un drama universal, nos obligan a recordar no sólo lo que ocurre en Hamlet, sino, más importante aún, qué sucede en la literatura que lo convierte en memorable, prolongando, de este modo, la vida del autor (El canon 49-50).

En general, entendamos, el acto hegemónico de reconocimiento es ese, máxime cuando hablamos de la conformación oficial-estatal del canon; de la conformación selectiva, que manifiesta una "forma de control, de denominación, de domesticación" que permite que las "contradicciones" sean "sistematizadas y los conflictos funcionalizados", al tiempo que "el poder [en minúsculas y mayúsculas] utilice el discurso como arma, como sofisma, como chantaje"

mediata, las acciones o los acontecimientos que se encuentran en el epicentro de los escándalos mediáticos resultan visibles a los ojos de terceras personas que no estaban presentes en el momento y en el lugar que sucedieron, y que podían haber estado situados en lugares muy distantes" (93-94). 
(Martín Barbero 69). A su vez, conviene mencionar que tal conformación implica algo más, importante en esta reflexión: el que muchos autores (los "talentos más débiles") se queden fuera debido a la ruindad selectiva de la Historia, o, en su defecto, a la inercia de la catalogación que no encuentra los parámetros necesarios para colocar en el estadio ceremonial las diferencias y los contrasentidos, los relatos alternos que potencian la dispersión (Zanetti); dispersión, en todo caso, que jamás desaparece y obliga a preguntarnos si acaso la pretendida falta de fuerza de algunos se debe a la elementalidad del planteamiento, o si acaso, a la descalificación grupal-institucional, que veda -durante algún tiempo- la consignación y el estudio de una estética impar, que establece sus fundamentos.

So pena de equivocarme en la lectura que siempre he hecho del canon mexicano, asumo que los esfuerzos por meter a los "talentos más débiles" en el carril del "Fundador" (Bloom, Anatomía 46) no se han detenido (háblese de los raros), y que ello ha contribuido a la concepción de proyectos valiosos, de alcances duraderos, que nos hacen pensar en la contundencia de variables como las de que no todo está escrito, en relación con la expresividad literaria; como las de que no todo está dicho, en relación con la suma de los fragmentos, con la estampa holista que se requiere en el proceso calificativo de la esteticidad. ${ }^{2}$

\footnotetext{
2 "Los últimos veinte años del siglo XX en Latinoamérica han estado marcados por dos procesos que, observados con detenimiento, conforman los aspectos nucleares de una época intensa en cuanto a la revisión crítica del canon literario latinoamericano. Por un lado, nos referimos a la emergencia notable de una zona del discurso literario que busca renovar las formas narrativas y que prontamente es identificada como 'la nueva narrativa' ya sea latinoamericana, ya sea acotada a las diversas regiones ('nueva narrativa chilena', 'nueva narrativa mexicana', colombiana, argentina, etc.). Hablamos de escritores o grupos de escritores nucleados en torno a manifiestos o antologías en los cuales se percibe una búsqueda de cambio y de revisión de lo que, hasta el momento, se entendía por 'la literatura latinoamericana'. Por otro lado, nos referimos a un proceso muy complejo y aún no cerrado, de revisión y transformación de la praxis crítica latinoamericana, de los insumos y objetos con que hasta los años ochenta definía su hacer. Proceso de transformación que se comprende en relación a la llegada e impacto de las
} 
En el entendido, entonces, de que la creación permuta a los ojos del espectador, hemos de pensar en que proyectos como los encabezados por el escritor Mario González Suárez han resultado refrescantes y, en cierto sentido, demoledores, al proponer la idea de que todavía queda mucho camino por andar en la conformación definitiva de los volúmenes de una enciclopedia total de las literaturas mexicana y latinoamericana, respectivamente. ${ }^{3}$ Hablo, en concreto, de sus estimulantes recopilaciones y notas plasmadas en proyectos como Paisaje del limbo. Una antología de la narrativa mexicana del siglo XX, publicado por Tusquets Editores en 2001, y de su labor coordina-

nuevas teorías metropolitanas comprendidas dentro del amplio horizonte de la Posmodernidad: los estudios culturales, las teorías poscoloniales, los estudios de género, los estudios de la subalternidad. Así, a principios de los ochenta, la crítica latinoamericana que hasta la década anterior se debatía entre los 'sociologismos' y el 'inmanentismo' en que el estructuralismo había devenido, se ve en la necesidad de modernizar, 'adaptar' tanto las nuevas teorías como los objetos a un nuevo orden epistemológico. Emerge un proceso de revisión del canon, de los autores, y de las matrices narrativas legitimadas en la historia de nuestra literatura; desde el realismo hasta el realismo mágico comienzan a ser reprocesadas desde otras teorías y, si por un lado encontramos una apertura del canon latinoamericano hacia géneros que habían quedado por largo tiempo relegados de la categoría 'literarios' (las crónicas, las cartas de relación, el testimonio, etc.) por el otro, encontramos que géneros y formas narrativas otrora 'representativos' de la 'Latinoamericanidad' comienzan a ser mirados con recelo: el realismo mágico devenido macondismo, exotismo, criollismo" (Sabo 1-2).

${ }^{3}$ En este aspecto me hago eco de las palabras de Rafael Gutiérrez Girardot, las cuales enfatizan el poder del centralismo literario tan típico de los países latinoamericanos y que suele definir las fronteras de una tradición nacional sin considerar las diferencias de fondo y conocer con amplitud la horadación que estas mantienen con sus sistemas de origen: “Es precisamente el 'municipalismo' de la historiografía literaria nacionalista el que plantea un problema . . . de la historiografía literaria, esto es, el de la valoración o, si se quiere, el de los criterios de valor con que ha de juzgarse una obra literaria para ser considerada digna de entrar en la monumental historia de la literatura de cada 'Republiqueta'. En este campo reina la más absoluta arbitrariedad y confusión. Para todos los nacionalistas, el supremo valor es un criterio indefinible e inaceptable empíricamente: el 'ingenio' o 'estilo' español, el 'alma argentina', la 'peruanidad', la 'sensibilidad propia del ambiente chileno', la 'virilidad' o la 'femineidad', etc.” (84-85). 
dora de la colección literaria Singulares, auspiciada por la Dirección General de Publicaciones del Consejo Nacional para la Cultura y las Artes, a partir del año 2009, con la aparición de un título tan macabro y fuera de serie como Tadeys (2005), del finado autor argentino Osvaldo Lamborghini.

De hecho, el que mencione aquí a Lamborghini es relevante, pues, me parece, nadie como él para representar el modelo del escritor marginal por antonomasia; el modelo del escritor maldito que se ha quedado fuera del canon por lo que implica su literatura, no solo en el contexto hispanoamericano sino también mundial: la evidencia pletórica de un discurso transgresor que no se aviene a las convenciones; la apuesta por un ejercicio creativo-destructivo que violenta la tradición; la búsqueda de lo prohibido como praxis recurrente; $y$, sobre cualquier otro tema que se mencione, la concepción de una obra personal que surge por las necesidades comunicativas del creador ajeno a los intereses grupales, sean estos de cualquier clase. ${ }^{4}$ En cierto modo, tales características literarias son las que se hallan presentes en los trabajos de relegitimación emprendidos por González Suárez, partiendo del criterio de que existe un tipo de creación escrita que no ha sido parte del lugar común y, por lo tanto, no ha estado en boca de quienes definen la valía de una obra artística y se encargan de difundirla a los cuatro vientos de la esfera cultural. Por ello, infiero, es de admitirse el hecho de que la antología Paisajes del limbo y la colección Singulares le permiten abonar a su manera a la

\footnotetext{
${ }^{4}$ González Suárez: "Me interesa Lamborghini porque contradice las buenas intenciones y la ñoñería de buena parte de la literatura latinoamericana oficial, porque no es folklórico, no trata de explicar 'lo nuestro', no lucra con los indios ni los pobres. Al explorar a fondo la realidad pone en evidencia que la literatura no es ni puede ser edificante. La literatura no sirve para nada y ese es su servir ... Tadeys trata de la oscuridad en que flota la conciencia, que es apenas una pequeña isla en medio del impredecible mar del inconsciente. La violencia, la depredación, el crimen, la locura no es algo de los 'otros', no son temas de nota roja, son los impulsos naturales de la psique, que sólo los moralistas y timoratos creen que han domesticado con su religión, su ideología y su pretendida civilización" ("Conversa con el escritor Mario González Suárez”).
} 
comprensión de que en el escenario conflictivo de las letras nacionales existen anomalías sugerentes que se deben tomar en consideración, principalmente si lo que se busca es descubrir la lógica real, no distorsionada -no institucionalizada- de la expresión escrita; una expresión, en el mejor de los casos, diversa, múltiple, caótica, que manifiesta con frecuencia la recusación de lo diferencial:

El caso de Paisajes del limbo [comenta González Suárez en una entrevista] es literatura específicamente de autores mexicanos. Nuestra percepción de la literatura mexicana está sesgada por intereses extraliterarios. Está demasiado pervertida por los intereses de la patria, y nos cuesta mucho trabajo acceder a otros discursos. Así como para una secta protestante es muy difícil leer las cartas de Pablo fuera de sus prejuicios, de su manual, para nosotros es muy difícil acceder a cierta literatura mexicana. Nos estorba la nacionalidad para recibirla. Cuando empiezas a comparar la literatura que se hace en México y en otros países de lengua española, que es un poco la idea de la colección Singulares, ves cómo funciona la lengua en los distintos lugares donde se habla . . . La colección Singulares es uno de esos espacios inesperados que surgen dentro de las instituciones, donde se pueden proponer obras imprescindibles para una literatura, o por lo menos para una lengua. Son obras que han estado relegadas u olvidadas por el mercado editorial o por las instituciones que publican libros. Para una editorial, estos títulos no significan nada porque no son un éxito en el mercado. Para las instituciones, generalmente no son obras conocidas, comentadas. Pero son obras imprescindibles de la literatura en lengua española. Son libros que hay que leer, porque luego la gente anda envileciendo su vida leyendo novedades editoriales. Esta colección se propone mostrar a los lectores obras muy importantes, obras de lectura imprescindible, sobre todo para la gente más joven (Gándara). 
Efectivamente, el que González Suárez apueste por esta clase de literatura se debe, en parte, a sus predilecciones, las mismas que conjugan, de acuerdo con Mauricio Carrera y Betina Keizman, muchas de las aportaciones hechas por la literatura fantástica,

entendida ésta no como lo propio del cuento de hadas con sus dragones y elfos sino -conforme a lo establecido por Roger Caillois- como lo sobrenatural que rompe la coherencia universal, como el prodigio que se torna "una agresión prohibida, amenazadora, que quiebra la estabilidad de un mundo en el cual las leyes hasta entonces eran tenidas por rigurosas e inmutables" (185-186).

Sin duda, en el fondo de los proyectos Paisajes del limbo y Singulares se encuentra esta inclinación, por parte de González Suárez, a reconocer las figuras representativas de un modelo literario vinculado con los fundamentos estéticos de su obra. Pero además de tal declaración de principios, que establece las coordenadas que dirigen los pasos de su creatividad, es notorio que el asiento de dichos proyectos - a la par- se haya en la necesidad del autor por ampliar los registros del canon, en la urgencia que enfatiza de extender sus correlaciones bajo el principio de que los sistemas literarios siempre son cambiantes y diversos, y, efectivamente, en ellos las estructuras dinámicas, rizomáticas, innombrables, a veces no encuentran su lugar. Todo ello, en cierto modo, es lo que me hace pensar en que el objetivo perseguido por González Suárez es el de abrir una brecha en el tupido bosque de los paradigmas del canon mexicano para, después, introducir las claves de una expresión que poco o nada se relaciona con las angustias de las influencias y los epicentros de la literatura reconocida.

En el caso de que tuviera que etiquetar esta expresividad no dudaría en acudir al mote de "lo menor", $\tan$ bien estudiado por Gilles Deleuze y Félix Guattari en el momento en el que abordan los detalles del corpus kafkiano y plantean que hay manifestaciones escritas que, en esencia, buscan separarse de los criterios admitidos y ponderar una pulsión centrífuga, opuesta a los baluartes de la centralización y de las estructuras verticales. Afirman estos autores: 
Una literatura menor no es la literatura de un idioma menor, sino la literatura que una minoría hace dentro de una lengua mayor. De cualquier modo, su primera característica es que, en ese caso, el idioma se ve afectado por un fuerte coeficiente de desterritorialización ... La segunda característica de las literaturas menores es que en ellas todo es político. En las "grandes literaturas", por el contrario, el problema individual (familiar, conyugal, etcétera) tiende a unirse con otros problemas no menos individuales, dejando el medio social como una especie de ambiente o de trasfondo ... La tercera característica consiste en que todo adquiere un valor colectivo. En efecto, precisamente porque en una literatura menor no abunda el talento, por eso no se dan las condiciones para una enunciación individualizada, que sería la enunciación de tal o cual "maestro", y que por lo tanto podría estar separada de la enunciación colectiva (28-30).

Considerando los ejemplos históricos que se han afianzado a través de los años, González Suárez plantea la impostergable tarea de admitir las anomalías, los punto de fuga, los casos de aquellos que se han visto opacados por la sombra alargada del modelo-árbol-tronco, para parafrasear una idea bastante cara en el texto más representativo de los filósofos antes mencionados: Capitalismo y esquizofrenia $(1972,1980)$. Por consiguiente, sugiero que a la manera de un escritor como Roberto Bolaño -en esa poética cifrada y clasificatoria del santoral personal que es Entre paréntesis (2004), organizada póstumamente por Ignacio Echevarría-, el escritor mexicano se dé a la tarea de rescatar los nombres de diversos autores que han brillado por su ausencia en las historias literarias del país no obstante contar con una obra llamativa, que engloba nuevos designios en lo relativo a la creación y jamás postula normas de carácter moral:

Normalmente los lectores confunden literatura con entretenimiento. Con algo que tiene que ser edificante, agradable, bonito, que transmita valores. Pero la literatura en realidad no tiene nada que ver con eso. Esas son necesidades de institu- 
ciones, de familias, de religiones. La literatura está totalmente al margen de esas expectativas no literarias que tienen los lectores. La literatura es algo que no sirve para nada. Y en su no servir está su servir. A la literatura no le interesa gustar, complacer, ni edificar, ni hacer mejor a la gente, ni darle algo que no ha recibido en su casa, en su religión o en su nacionalidad. La literatura va por su propio camino abriendo la conciencia humana. Hay una exigencia en lo literario (Gándara).

El que tal reconocimiento, por lo demás, se vincule con el desgaste de las figuras modélicas, que ya no consienten -según el abordaje que se realice- nuevas ópticas de interpretación, quizás aclare el porqué de las selecciones de González Suárez; pero también, me parece, es importante que aceptemos que en dicho movimiento de piezas quizás se impone la aceptación de una realidad diferente, que exige otra fundación; de una realidad distinta, que influye -sobremanera- en lo que se lee y escribe, se retoma y continúa tras instaurar una forma estética, tal vez, más apegada a las necesidades expresivas de la actualidad y de una generación que ha intentado "individual y colectivamente, fisurar la lógica imperante en el medio" (Chávez Castañeda y Santajuliana 12).Con esto, cabe afirmar, no es que González Suárez invalide los modelos del canon, ni que tampoco los pretenda desdibujar; simplemente, en su caso, persigue el interés de ampliar la nómina de los olvidados, de los secundarios, de los "talentos más débiles", ya que ellos también contribuyen al entendimiento y la comprensión de los matices existentes en el tratamiento literario de la realidad, o de su representación.

De acuerdo con lo que plantea en la introducción de Paisaje del limbo, lo que a González Suárez realmente le interesa es rescatar del olvido a un grupo de escritores, al menos en el caso mexicano, que se apegan con convencimiento a las facetas de su "mitología personal" a fin de ubicarlos, enseguida, en el lugar que les corresponde como representantes de una literatura inclasificable, que promueve imágenes divergentes de la extrañeza y la singularidad propias de la experiencia del yo. Asegura González Suárez a este respecto: 
Los narradores del limbo son quienes han revelado su mitología personal, los que han sabido desplegar una "mitología espontánea", como dice Bachelard, y han dado el brinco que a cada hombre exigen la conciencia y el valor para no vivir preso de natura, la raza, las doctrinas ni la religión. Pues, según Joseph Campbell, "de la misma forma que en el pasado cada civilización era el vehículo de su propia mitología, desarrollando su carácter a medida que su mito iba siendo interpretado, analizado y elucidado por sus mejores mentes, en el mundo moderno - donde la aplicación de la ciencia a los campos de la vida práctica ha borrado todos los horizontes culturales, de tal forma que no se puede desarrollar una civilización aislada- cada individuo es el centro de una mitología propia, de la que su carácter inteligible es su Dios Encarnado, por así decirlo, el cual debe ser descubierto por su conciencia en una búsqueda empírica" ("Banquete" 10).

Amparado mayormente en la noción del "monomito", explicado por el célebre psicoanalista en el clásico El héroe de las mil caras (1949), González Suárez apuesta en esta labor antológica por detenerse en los nombres de escritores como -por orden de apariciónFrancisco Tario, Juan Manuel Torres, Pedro F. Miret, Jesús Gardea, Guadalupe Dueñas, Efrén Hernández, Arqueles Vela, Daniel Sada, Álvaro Uribe, Ricardo Elizondo Elizondo, Salvador Elizondo y Juan Vicente Melo: autores, todos, que a estas alturas y en honor a la verdad suelen recibir la atención de la crítica especializada y han sido distinguidos, en especial los más recientes (Sada, Uribe, Elizondo) con importantes premios literarios (de eco internacional), pero que, se mire donde se mire, resultan de ubicación difícil, nunca se prestan a definiciones categóricas y, sobre cualquier detalle que se considere, expresan las claves de una "mitología personal", en el sentido que González Suárez le brinda: o sea, en el de entender que el creador conforma su propio universo, en el de pensar que el verdadero artista es un desadaptado que se distancia de las normas imperantes, sin importar que vengan de la familia, del Estado o de cualquier otra instancia de poder que determine los 
contenidos y las formas del mensaje que se pretende comunicar. Esto, sin duda, lo aclara González Suárez al hablar del significado del título de su antología e indicar que

por limbo no ha de entenderse aquí un peligroso kindergarten para niños no bautizados, ni jardín de locos para inteligencias paganas. Limbo es un lugar donde transita libremente el alma y sabe que ella misma es el espacio. Allí se ubica el sujeto como centro de su soledad y su conciencia; su territorio le parece finito porque no se extiende más allá de donde la alcanza la vista, pero al moverse descubre que el horizonte también avanza. A tal esfera se le han puesto muchos nombres, tal vez con la intención de facilitar su estudio: es el ámbito de los sueños, el mito, la poesía, la imaginación, la infancia, el inconsciente o el mundo de los muertos. Y nos percatamos del limbo porque este mundo y aquél están conectados a través de nuestra mente. Ser hombre significa ser umbral ("Banquete" 11).

Con respecto a las temáticas que imperan en la colección Singulares, es fácil detectar que González Suárez recobra esta idea, no sin antes aclarar que su planteamiento ahora presenta nuevos alcances debido a que no solo está interesado en promover las obras de escritores mexicanos del siglo XX: también, le interesa sumar a la nómina de raros del país los nombres de otros que, en el resto de Hispanoamérica, han sido vistos como ejemplo cabal de animadversión hacia las convenciones estéticas, o que de plano se dedican a destruirlas. Basta, por tanto, hacer un breve repaso de esta lista para deducir el tipo de objetivos buscados, que - pienso- son los siguientes: 1) rescatar del olvido (ad litteram) a aquellos escritores que abordan temáticas reconocibles, las cuales forman parte del pan nuestro de cada día y contribuyen, me parece, a la fácil tipificación de un periodo; 2) promover a aquellos otros que no se adaptan a los esquemas formales al uso, ni mucho menos a los tópicos socorridos, con el objeto de presentar una visión diferente de las cosas que se encuentra a años luz de las que establecen las instituciones y los grupos de poder, se entiende, relacionados con la cultura, y 
3) presentar, por último, los nombre de quienes se han ganado con creces un prestigio internacional y no obstante en México han tenido escasa circulación y, más bien, han formado parte de las lecturas de culto de un puñado de iniciados que pregonan las cualidades estéticas de sus obras.

Dicho lo cual, no está de más mencionar rápidamente los títulos y los autores presentados en la colección Singulares, puesto que nos permite vislumbrar los alcances del proyecto de González Suárez - proyecto que, huelga insistir, no busca sino ampliar los márgenes del canon mexicano y latinoamericano para incorporar a quienes siempre han estado en el limbo de lo marginal o se han dedicado a desarrollar una obra extraña, de clasificación dificultosa-.

Por orden de aparición, los títulos y los autores recuperados son: Tadeys, de Lamborghini; Cuentos (casi) completos, del cubano-estadounidense Calvert Casey; Camaradas (1959) y Soledad (1944), de Rubén Salazar Mallén; La zapatería del terror (1978), de Pedro F. Miret; La ruina de la casona (1921), de Esteban Maqueo Castellanos y Ciudad (1943), de José María Benítez, publicados en 2010; Aquí abajo (1946), de Francisco Tario, en 2011 y, un año después, la autobiografía Vida incompleta. Ligeros apuntes sobre mujeres en la vida real (1927), de Elena Arizmendi y el libro de aventuras Piratas de América (1678), de Alexander O. Exquemelin.

Resumiendo, es de destacarse que estos textos a González Suárez le garantizan poner en circulación un paquete de obras escritas que, en su opinión, deben ocupar un lugar destacado en las historias literarias, en virtud de que cuando se les compara con aquellas que resultan imprescindibles demuestran una valía similar, incluso, en algunos casos superior, al brindarle al lector la oportunidad de comprender la existencia de determinados aspectos de carácter artístico que jamás se vislumbraron y estaban ahí. Igualmente, es innegable que los textos que componen la colección aluden a los matices de esa "mitología personal", en tanto que refieren los rasgos de una "literatura menor", contraria a los intereses mayoritarios e indagadora de lo secreto: lo reitero, de esa realidad personal que solo se comunica cuando el escritor se sitúa en el "centro de su soledad y su conciencia" y gracias a tal colocación propone un ordenamiento alterno del mensaje. 
Como afirmaba al principio de estas notas, me parece que la construcción del canon siempre es excluyente; y más cuando intervienen intereses particulares que subrayan la validez simbólica de un esquema de producción y mantienen "una trayectoria de múltiples facetas que propone ideas de regulación, valoración y tradición artística" (Castillo 39). Ante esto, proyectos de reintegro como el que aquí he tratado de comentar no solo refrescan el panorama cotidiano: a la par, ayudan a consumar un acto de contrición capaz de enmendar la plana y manifestar la fragilidad de los paradigmas aceptados si caemos en la cuenta de que, por desgracia, hay muchas cosas que se han pasado de largo y a pesar de ello, o gracias a ello, reclaman su incorporación.

Por donde se observe, la propuesta de González Suárez admite una necesidad: la de la ampliación canónica; y sus esfuerzos, convertidos en antologías rehabilitadoras y colecciones singulares, son la muestra visible de que las nuevas generaciones de escritores (los nacidos a partir de la década de los 60) están a la búsqueda del cambio, tal vez porque los viejos valores se han corroído o tal vez porque, definitivamente, aportan más y mejores respuestas para comprender la lógica de las variables creativas de la actualidad.

\section{Obras consultadas}

Arizmendi, Elena. Vida incompleta. Ligeros apuntes sobre mujeres en la vida real. México: CONACULTA, 2012.

AA. VV. Paisaje del limbo. Una antología de la narrativa mexicana del siglo XX. Selecc. y notas de Mario González Suárez. México: Tusquets Editores, 2001.

Bartra, Roger. "Poder, intelectuales y opinadores". Letras Libres 137. (2010): 18-19.

Benítez, José María. Ciudad. México: CONACUlTA, 2010.

Bolaño, Roberto. Entre paréntesis: ensayos, artículos y discursos. Ed. Ignacio Echeverría. Barcelona: Anagrama, 2004.

Bloom, Harold. El canon occidental. Tr. Damián Alou. $3^{\text {a }}$. ed. Barcelona: Anagrama, 1997. 
- Anatomía de la influencia. La literatura como modo de vida. Tr. Damián Alou. México: Taurus, 2011.

Campbell, Joseph. El héroe de las mil caras. Psicoanálisis del mito. México: Fondo de Cultura Económica, 1998.

Carrera, Mauricio y Betina Keizman. El minotauro y la sirena. Entrevistas-ensayos con nuevos narradores mexicanos. México: CONACULTA/ Lectorum, 2001.

Casey, Calvert. Cuentos (casi) completos. México: CONACULTA, 2010.

Castillo, María Esther. "La presión interdiscursiva del canon literario en América Latina”. La palabra y el hombre 128. (2003): 39-44.

Chávez Castañeda, Ricardo y Celso Santajuliana. La generación de los enterradores. Una expedición a la narrativa mexicana del tercer milenio (escritores nacidos en la década de los sesenta). México: Nueva Imagen, 2000.

Deleuze, Gilles y Féliz Guattari. Kafka. Por una literatura menor. Tr. Jorge Aguilar Mora. México: ERA, 1990.

- Capitalismo y esquizofrenia. Tr. José Vázquez Pérez y Umbelina Larraceleta. 6a . ed.Valencia: Pre-textos, 2004.

Exquemelin, Alexander O. Piratas de América. Ed. Manuel Sol. México: CONACULTA, 2012.

Gándara, César. "Sobre las obras imprescindibles. Entrevista con Mario González Suárez”. Justa, lectura y conversación. Editorial Jus. 2010. Web. 20 diciembre 2013.

González Suárez, Mario, selecc. y notas. "Banquete en el limbo". Paisaje en el limbo. Una antología de la narrativa mexicana del siglo XX. México: Tusquets Editores, 2001.

—. "Conversa con el escritor Mario González Suárez". El Universal. 11 mayo 2010. Web. 3 enero 2014.

Gutiérrez Girardot, Rafael. "Revisión de la historiografía literaria latinoamericana". Pizarro 79-90.

Lamborghini, Osvaldo. Tadeys. México: CONACUlTA, 2010.

Maqueo Castellanos, Esteban. La ruina de la casona. México: CONACULTA, 2010.

Martín-Barbero, Jesús. Oficio de cartógrafo. Travesías latinoamericanas de la comunicación en la cultura. Chile: Fondo de Cultura Económica, 2002. 
Miret, Pedro F. La zapatería del terror. México: CONACULTA, 2010.

Pizarro, Ana, coord. Hacia una historia de la literatura latinoamericana. México: El Colegio de México/Universidad Simón Bolívar, 1987. Rabossi, Eduardo. En el comienzo Dios creó el canon. Biblia berolinensis. Argentina: Gedisa Editorial, 2008.

Sabo, María José. "Crítica y revisión del canon de la literatura latinoamericana: apuntes de una discusión abierta". Actas del II Congreso Internacional "Cuestiones críticas". Centro de Estudios de Literatura Argentina; Centro de Teoría y Crítica Literaria de la Facultad de Humanidades de la Universidad Nacional de Rosario. 2009. Web. 2 enero 2014.

Salazar Mallén, Rubén. Camaradas. Soledad. México: CONACULTA, 2010. Tario, Francisco. Aqui abajo. México: CONACUlTA, 2011.

Thompson, John. B. El escándalo político. Poder y visibilidad en la era de los medios de comunicación. Barcelona: Paidós, 2001.

Zanetti, Susana. "¿Un canon necesario? Acerca del canon literario latinoamericano". Vozy escritura 10. (2010): 227-41. 